\title{
Regionalização do turismo: uma análise espacial do Arranjo Produtivo Local Rota da Amizade'
}

\author{
Tourism regionalization: a space analysis of Local Productive \\ Arrangements Route of the Friendship
}

\author{
José Elmar Feger \\ Milton Luiz Wittmann? \\ Luciana Davi Traverso Nodari \\ Marcos Luiz Filippimt \\ Fábio Lazzarottí
}

\section{Resumo}

A temática deste trabalho é a regionalização do turismo baseado na teoria dos espaços. 0 campo de estudo adotado foram os municípios pertencentes ao Arranjo Produtivo Local Rota da Amizade, no Oeste catarinense, por ser um projeto em desenvolvimento e servir, portanto, como um caso de pesquisa. O objetivo central foi caracterizar as presenças das categorias espaciais possíveis, com base na localização dos atrativos turísticos no território. Metodologicamente, constitui-se em uma pesquisa de levantamento descritivoanalítico, fundamentada em dados empíricos ou coletados em fontes bibliográficas $e$ documentais. $O$ trabalho, de acordo com o modelo proposto de estudo, evidenciou, em seus resultados, que a região em epígrafe possui quatro centros de distribuição, dois centros de excursão e um centro de estada. Contudo este trabalho teve limitantes nos aprofundamentos relativos à territorialidade, em função da inserção do turismo em áreas utilizadas para outras atividades não-turísticas e questões relativas à hierarquização de fatores.

Palavras-chave: espaço turístico; região turística; atrativos turísticos.

\section{Abstract}

The thematic of this work is the regionalization of the tourism, which theoretical basis was the theory of the tourist space. The study field adopted was the cities pertaining to the Productive Arrangement Local Route of the Friendship in the western region of Santa Catarina State, for being a project in development and to serve as a research case. The

\footnotetext{
${ }^{1}$ Mestre em Desenvolvimento Regional da Universidade do Oeste de Santa Catarina e doutorando em Desenvolvimento Regional pela Universidade de Santa Cruz do Sul - E-mail: joseelmar.feger@unoesc.edu.br - Endereço: Rua Jovino Bittencourt 41 Ap. 302 - CEP 89600-000 Joaçaba $\mathrm{SC}$

${ }^{2}$ Doutor em Administração da Universidade Federal de Santa Maria - E-mail: wittmann@ @rofwittmann.com - Endereço: R. Duque de Caxias 2.400 Ap. 201 CEP: 97060-210 Santa Maria - RS

3 Mestre em Turismo e Hotelaria da Universidade do Oeste de Santa Catarina e doutoranda em Administração pela Universidade Mackenzie - E-mail: luciana.nodari@ unoesc.edu.br - Endereço: R. José Bonifácio, 92 CEP: 89610.000 Herval D’Oeste - SC.

Mestre em Turismo e Hotelaria da Universidade do Oeste de Santa Catarina - E-mail: marcos.filippim@unoesc.edu.br Endereço: R. Frei Edgar, 111 Ap. 103 CEP: 89600.000 Joaçaba - SC

5 Mestre em Administração da Universidade do Oeste de Santa Catarina e doutorando em Administração e Turismo pela Univali - E-mail fabio.lazzarotti@unoesc.edu.br Endereço: R.Antônio Nunes Varela, 1212 Ap. 41 CEP: 89600-000 Joaçaba - SC
} 
central objective was to characterize the presences of the possible space categories, from the localization of tourist attractions in the territory. It is a research of descriptionanalytical survey, based on the empirical collected data and research in bibliographical sources and documents. The work, in accordance with the considered model of study, evidenced in its results that the region in possesses four distribution centers, two excursion centers and a sojourn center. However, this work had boundaries in deepening related to the territoriality, because of the tourism insertion in areas used for other nontourist activities and questions related to the hierarchy of factors.

Keywords: tourist space; tourist region; tourist attractive.

\section{Introdução}

O turismo, com base em uma abordagem regional, está sendo estimulado como fator de desenvolvimento endógeno, especialmente após o Programa de Regionalização do Turismo - Roteiro do Brasil (BRASIL, 2004). Observa-se que a fundamentação consiste em assimilar-se a noção de território como espaço e lugar de interação do homem com o ambiente, originando diversos modelos organizacionais de relacionamento entre a natureza, a cultura e os recursos.

Verifica-se, na justificativa desse programa, que, na delimitação do território, há uma forte relação com os poderes constituídos (nacional, estadual, municipal), porém com uma conformação regional baseada na negociação com os representantes do território. Fica clara a intenção dos responsáveis pela formulação do programa em romper com os conceitos tradicionais de regionalização, quando destacam que "[...] deve-se perceber o conceito como um esforço coordenado de ações integradas entre municípios, estados e países" (BRASIL, 2004, p. 9).

O fato de buscar-se a participação dos atores sociais para a elaboração do planejamento e a implantação das estratégias na ordenação dos arranjos produtivos locais demonstra superar a visão estritamente setorial do desenvolvimento e aceitar que os vínculos de parceria, integração e cooperação dos setores geram possibilidades mais amplas de bem-estar para as populações. Contudo, existem algumas questões que limitam o alcance de resultados mais promissores:

a) envolvimento da sociedade, na definição de estratégias de desenvolvimento, tende a caracterizar-se como uma forma de enfrentar os pressupostos essencialmente quantitativos adotados pelos modelos de crescimento, os quais levam a disparidades econômicas e ao abandono de recursos locais em virtude da concentração excessiva na localização dos fatores exógenos de produção. Desse paradigma surge a existência de poucas referências ao desenvolvimento endógeno (mobilização dos próprios recursos), ascendente (protagonismo dos agentes locais), autocentrado (centrado nas necessidades da própria comunidade), sustentável (garantia de utilização dos recursos também por gerações futuras), cujo sentido está parcialmente inserido no conceito de desenvolvimento local (CAVACO, 1999). Uma limitação que ocorre nesse processo, no tocante ao turismo, é o nível de conhecimento, muitas vezes incipiente, sobre o funcionamento do sistema turístico, por parte dos atores envolvidos no planejamento 
regional, levando a decisões baseadas em interpretação superficial do potencial turístico e, por conseqüência, a estratégias pouco consistentes.

b) A análise do território, como um instrumento de poder, ou seja, quem domina ou influencia quem nesse espaço, como alerta Souza (1995), pois o campo de forças que se forma numa região é bem mais amplo, envolvendo um número maior de instituições, as quais, muitas vezes, têm melhor condição de domínio ou de fazer valer seus interesses. No caso do sistema turístico, conforme a teoria das restrições (GOLDRATT, 1994), parece ser a demanda que possui a condição de comando e, nesse sentido, teoricamente, os municípios ou locais com uma hierarquia maior de atrativos (aqueles que possuem condições de atrair público de maior distância), parecem ser os que apresentam melhores condições de regular o fluxo turístico. Entretanto, em princípio, esse aspecto não está recebendo atenção adequada nos projetos em andamento (pelo menos nos acompanhados pelos autores desta pesquisa). De maneira geral, os processos de regionalização ocorrem em áreas delimitadas e observando critérios político-administrativos de associações de municípios, fazendo com que algumas decisões sejam tomadas a fim de incorporar agentes e setores que não necessariamente agregam valor, o que limita a oferta de um produto turístico mais qualificado.

c) A regionalização do turismo, segundo Boullón (2002), está fortemente ligada à localização dos atrativos turísticos, o que pode implicar descontigüidade de áreas, levando à formação dos chamados territórios-rede (ALEXANDRE NETO, 1997; SOUZA, 1995) e gerando uma complexa malha de nós, cujos contatos com o espaço real se localizam em apenas alguns pontos do espaço concreto, passando a disputar com outras redes superpostas à mesma área de influência econômica. Essa última percepção leva à constatação de que, por ser o turismo intensamente ligado à localização dos atrativos, faz com que o turista se desloque por territórios nãoturísticos, podendo, caso não se adotem medidas adequadas, prejudicar a imagem da região. Segundo Petrocchi (2001), o sistema turístico é composto por uma infinidade de subsistemas e tem o seu desempenho dependente dos de cada uma das partes que o compõem.

Aquilo que resultar do desempenho de todos os subsistemas é o que define o nível de competitividade do sistema como um todo, dentro de um mercado altamente concorrido. A falta de oferta de serviços competitivos (qualidade-preço-imagem) ameaça a sobrevivência do sistema (PETROCCHI, 2001, p. 28).

Depreende-se que a competitividade do sistema turístico de uma região depende da possibilidade de interação com os demais sistemas existentes no território, inferindo-se que, em certa medida, subordina-se a fatores externos (territórios não-turísticos) ao sistema para que seja competitivo.

Focou-se o estudo aqui apresentado na discussão sobre o terceiro aspecto, pois é necessário conhecer, em primeiro lugar, a localização dos atrativos, determinando-se os pontos em que os elementos turísticos tocam o espaço concreto, para, posteriormente, aprofundar os conhecimentos de sua interação com os demais sistemas econômicos e sociais que ocupam o mesmo território.

Trata-se, pois, de um estudo exploratório, de cunho descritivo, com base em um caso ilustrativo - o Arranjo Produtivo Local Rota da Amizade - que está em estruturação na 
região Meio-Oeste do estado de Santa Catarina. Pode-se considerá-lo exploratório, pois, de acordo com Seakaran (1992), é utilizado quando se objetiva compreender a natureza do problema sobre o qual poucos estudos foram realizados a fim de entender o fenômeno que se deseja observar. Caracteriza-se, também, como um estudo descritivo, uma vez que busca retratar os aspectos relevantes do fenômeno observado para confirmar a validade da teoria dos espaços na regionalização do turismo, como sugere Hair et al. (2005). Constitui-se também num estudo cross-sectional visto que a coleta de dados apresenta um recorte pontual no tempo em que o assunto foi pesquisado (SEAKARAN, 1992).

O contexto, em que se insere o estudo, é mais recente, entretanto se torna necessário ressaltar que é fruto de fatores históricos que se iniciaram no passado e resultado de processos articulados que ocorreram a partir de meados dos anos de 1990, com a proliferação pelo país de ações visando à conscientização e sensibilização da comunidade quanto à importância do turismo pelo Programa Nacional de Municipalização do Turismo (PNMT) da Embratur, que teve, como diretriz principal, a visão de que, à medida que os municípios entendessem que o turismo era importante para a sua economia, começariam a investir no setor, ressaltando-se que esse programa, no ano de 1998, atendia a 1.284 municípios brasileiros (OLIVEIRA, 2001).

Observa-se que, entre os diversos municípios que se inscreveram para participar do programa que visava basicamente treinar líderes que teriam a responsabilidade de organizar os conselhos municipais de turismo (OLIVEIRA, 2001), havia em torno de duas dezenas de municípios da região Meio Oeste do estado de Santa Catarina. Vale lembrar que, naquele período, somente três municípios da região já vinham explorando a atividade turística: Fraiburgo, Treze Tílias e Piratuba (ROTA DA AMIZADE, 2005).

Como consequiência desse processo, no início de 2001, representantes do Poder Público dos municípios de Videira, Pinheiro Preto e Tangará uniram-se para criar o Vale da Uva e do Vinho, com o objetivo de explorar a atividade turística em seus municípios. Estes entendiam que os municípios isoladamente não possuíam atrativos suficientes para motivar fluxos regulares de turistas, tendo como exemplo as estratégias de desenvolvimento do turismo adotadas pelos municípios da serra gaúcha.

Em outubro daquele mesmo ano, três empresários hoteleiros dos municípios de Treze Tílias, Fraiburgo e Piratuba reuniram-se com integrantes do Vale da Uva e do Vinho, para buscar maior diversificação de entretenimentos com o aumento dos atrativos turísticos, o que, conseqüentemente, melhoraria a taxa de ocupação dos estabelecimentos hoteleiros. As ações iniciadas, após esse encontro, começaram a apresentar resultados efetivos, de forma que, em fevereiro de 2002, lançou-se a Rota da Amizade - roteiro turístico regional integrado por seis cidades (Videira, Pinheiro Preto, Tangará, Piratuba, Treze Tílias e Fraiburgo) - cujo objetivo era o incremento turístico em todos os municípios envolvidos.

Em 2004, o Sebrae lançou o projeto nacional dos APLs (Arranjos Produtivos Locais), e os atores envolvidos com a Rota da Amizade iniciaram articulações para inseri-la nesse programa, a fim de qualificar as ações turísticas existentes nesses municípios por meio dos recursos provenientes desse projeto. Após ampla discussão entre o Sebrae, representantes da Rota da Amizade, Fundação de Turismo Vale do Contestado - CONTTUR —, visando definir os municípios que seriam contemplados com os recursos do projeto, concluiu-se que, em função da localização geográfica e do contexto socioeconômico, o município de 
Joaçaba deveria ser incluído no APL e, por conseqüência, na Rota da Amizade, que passou a contar com sete municípios.

As atividades para organização do arranjo produtivo local foram subdivididas em diversas etapas: iniciam-se com a seleção das empresas existentes no trade turístico e chegam até a prospecção de mercado e distribuição de material promocional (ROTA DA AMIZADE, 2005).

Após esse preâmbulo, que procurou situar o ambiente em que se realiza o estudo, neste texto serão relatados os resultados de uma pesquisa que teve por objetivo caracterizar e analisar a região turística, constituída pelos municípios que compõem o Arranjo Produtivo Local Rota da Amizade, com base na teoria do espaço turístico. Especificamente, identificaram-se as categorias espaciais em que se enquadrariam os sete municípios integrantes do projeto. Fundamentando-se nesse conhecimento, neste artigo propõem-se estratégias para o desenvolvimento do turismo regional; oferecem-se contribuições para ampliar o debate e instigar a realização de novos projetos de pesquisa e análise espacial do turismo; e disponibiliza-se um estudo de caso, que pode auxiliar no ensino e na discussão sobre regionalização do turismo.

Dispõe-se, ainda, neste artigo, a teoria dos espaços para analisar e configurar regiões com vistas ao planejamento do turismo, por possibilitar decisões com base na existência de atrativos turísticos e permitir a delimitação de áreas de planejamento. Diferencia-se dos procedimentos usuais que utilizam os limites político-administrativos, mas que são úteis para outras finalidades, porque, como demonstra Boullón (2002), impõe limitações para o desenvolvimento do turismo.

O artigo foi dividido em cinco seções: a primeira constituiu-se desta introdução. A segunda é conceitual, abordando a teoria dos espaços e a regionalização destacando os preceitos que nortearam a análise dos dados. Na terceira seção, apresentam-se os procedimentos metodológicos que foram utilizados para o levantamento dos dados empíricos que serviram de base ao estudo. A quarta seção ficou reservada à análise dos dados, na qual se faz uma descrição e discussão dos aspectos encontrados na região objeto de estudo. Finalmente, na quinta seção, apresentam-se as considerações finais que contemplam os principais aprendizados obtidos e as possibilidades de novos estudos necessários à complementação do conhecimento sobre turismo regional, além das limitações que envolveram a pesquisa.

\section{Regionalização do turismo com base na teoria dos espaços}

O interesse central do estudo, aqui apresentado, foi a regionalização fundamentada na localização dos elementos turísticos num determinado território: no caso, os municípios que fazem parte do Arranjo Produtivo Local Rota da Amizade do Oeste catarinense. Iniciase esta seção pela revisão sobre o Arranjo Produtivo Local e pelos conceitos sobre regionalização, seguindo pela caracterização dos elementos que se formam com base na teoria dos espaços.

\subsection{Arranjo produtivo e regionalização}


O conceito de arranjo produtivo ainda é tratado de forma controvertida, em razão da falta de uma nomenclatura única entre os autores que discutem o tema. Alguns tratam arranjos produtivos com os mesmos argumentos com que outros conceituam aglomerações (clusters), ou seja, como mera proximidade de empresas. Optou-se, neste estudo seguir, a linha de pensamento de Shmitt et al. (2004) e Paiva (2004) os quais entendem que um aglomerado (cluster) se configura como um primeiro estágio em que a concentração de empresas possibilita algumas vantagens de aglomeração ao conjunto de empreendimentos instalados em determinado território. Já o "arranjo produtivo local se caracteriza pela existência de fortes relações interfirmas, de interdependência e de um sistema próprio de governança que coordena as ações dos envolvidos" (SHMITT et al., 2004), considerando, outrossim, a sua importância para com o local e o regional, já que tanto aglomerações de empresas como arranjos produtivos prescindem da territorialização e, por conseguinte, da região.

O tema regionalização - embora exista atualmente certa complexidade para conceituar região, território e desenvolvimento - é importante nesse tópico. Vale lembrar que não há pretensão de esgotar o assunto, somente destacar alguns conceitos que serviram de pano de fundo ao estudo.

Milton Santos (2000) comenta que, no passado, havia critérios para a definição de regiões: os que se apoiavam nos dados da natureza por meio da combinação de elementos, como clima, vegetação e relevo, formando as denominadas regiões naturais; os que consideravam a região como o resultado de um longo processo de transformação da paisagem natural em paisagem cultural, evidenciando o arranjo dos campos, o sistema agrícola e o habitat rural, incluindo o dialeto e os costumes, constituindo um conjunto integrado de traços culturais, denominado regiões paisagem.

Alguns autores entendem a região como um produto social construído em determinados espaços, cujas condicionantes importantes são a distância, a localização, os transportes, a força de trabalho (BENKO, 1999), compreendendo que:

a região corresponde a uma área geográfica que constitui uma entidade que permite, simultaneamente, a descrição de fenômenos naturais e humanos, a análise de dados socioeconômicos e a aplicação de uma política. Funda-se em duas características principais: homogeneidade e integração funcional, e resulta, ao mesmo tempo, num sentimento de solidariedade vivida e em relações de interdependência com os restantes conjuntos regionais e com o espaço nacional e internacional (LAJUGIE e LACOUR, 1979 apud BENKO, 1999).

Massey, 1998 apud Silveira (2000) argumenta, nesse sentido, sugerindo que a especificidade e a identidade dos lugares que constituem uma região, podem ser apreendidas como resultado da construção de relações sociais, reunião e articulação que ocorrem simultaneamente num determinado lugar, organizando um "lugar de encontros".

Atualmente com as facilidades de comunicação e de transporte, por causa da globalização, ocorrem interferências constantes no seio das comunidades regionais. Nesse sentido,

[...] o espaço geográfico ganha novos contornos, novas características, novas definições. E, também, uma nova importância, porque a eficácia das ações está 
estreitamente relacionada com a sua localização. Os atores mais poderosos se reservam os melhores pedaços do território e deixam o resto para os (SANTOS, 2000, p. 79).

O autor continua, demonstrando que o âmbito territorial e social sofre mudanças numa relação dialética entre rigidez e flexibilização, baseadas em um conjunto de normas públicas, privadas, locais, globais, jurídicas ou informais.

Agora, neste mundo globalizado, com a ampliação da divisão internacional do trabalho e o aumento exponencial do intercâmbio, dão-se, paralelamente, uma aceleração do movimento e mudanças mais repetidas na forma e no conteúdo das regiões. [...], mas isso não suprime a região, apenas ela muda de conteúdo [...] a região continua a existir, mas com um nível de complexidade jamais visto pelo homem (SANTOS, 1996, p. 197).

Os territórios diferem de acordo com as suas características materiais e imateriais, ou seja, em razão de seus recursos biofísicos, humanos, relações sociais, modos de produção e suas culturas, que formam suas identidades territoriais e revelam os espectros, as formas e as intensidades de integração econômica e cultural dos lugares e regiões no âmbito de redes e sistemas socioeconômicos e espaciais hierarquizados (ROCA e OLIVEIRA, 2004). Nesse sentido, Santos (1996) argumenta que os processos ocorrem por meio de redes, cujos fluxos tornam-se mais densos, mais variados e multidirecionados, havendo diferentes redes recobrindo a superfície terrestre, as quais podem ser planejadas ou espontâneas, formais ou informais, temporárias ou permanentes, materiais ou imateriais, regulares ou irregulares.

Toda configuração territorial que existe, atualmente, é produto de movimentos sociais e políticos (HARVEY, 1992). Souza (1995) explica que território é um espaço definido e delimitado pelas relações de poder e nelas fundamentado. Caracteriza-se pela interação do homem com o solo formando uma unidade demarcada (visto como território nação), consistindo numa flexibilização, num campo de forças ou numa teia ou rede de relações sociais que, concomitantemente, com sua complexidade interna, define ao mesmo tempo um limite, uma alteridade: a diferença entre os membros da comunidade (insiders) e os de fora, os estranhos (outsiders). Em suma, territórios são relações sociais planejadas no espaço.

Com base nesses princípios, pode-se definir região de diversas formas. Por exemplo: considerá-la do ponto de vista das características naturais, históricas, da divisão social do trabalho, da ocupação do espaço por determinada etnia ou ainda levando-se em conta a divisão político administrativa, uma vez que se caracteriza pela delimitação de determinada área por órgãos governamentais. Região, portanto, pode abranger uma área do país, uma parte de um estado ou município e ser considerada como o espaço geográfico no qual ocorrem relações socioeconômicas.

Ao contrário do que se poderia pensar, levando-se em conta os efeitos da globalização, vem-se associando região às diferenças locais e alguns pesquisadores (CAVACO, 1999; FRANCO, 2000) têm articulado o conceito com vários fatores intervenientes do desenvolvimento local. Os argumentos utilizados em defesa são de que não é possível haver desenvolvimento somente com o crescimento econômico, fator extremamente importante, mas que não se basta por si só. É preciso, segundo eles, levar em conta além do 
capital monetário da forma que é tratado pelos economistas, também o capital humano (conhecimento e capacitação das pessoas), o capital social (a estrutura e a capacidade de integração dos atores visando trabalhar conjuntamente e organizando-se por meio de entidades) e o capital ecológico (utilização racional dos recursos disponíveis na natureza). Desenvolvimento passa a se constituir pela integração desses capitais de forma conjunta e articulada.

O desenvolvimento tende a ocorrer localmente pela existência dos capitais relacionados com a ocupação de um espaço. Para rivalizar-se, cada local identifica seus fatores de sucesso e os utiliza para criar valores competitivos, permitindo concorrer com as diversas regiões do planeta e oferecendo produtos e serviços diferenciados (PORTER, 1990; 1999).

Ressalte-se a importância da integração das diversas instituições públicas e privadas, em torno de um projeto comum em que, cada qual, desempenhe o seu papel a fim de que o processo ocorra de forma harmoniosa e planejada. $\mathrm{O}$ aumento de competitividade local prescinde de um sistema econômico estruturado, dele fazendo parte os governos locais e estaduais e de um fórum de desenvolvimento regional com a função de articular os projetos pela integração das instituições locais e regionais com atuação conjunta com os segmentos públicos e privados por meio de associações, consórcios de produção ou exportação. Também deve existir, na região, um observatório econômico e um centro tecnológico capazes de avaliar o mercado internacional e gerar conhecimentos que possibilitem a elevação dos níveis de produtividade das empresas. Todos esses agentes, de forma interconectada, permitem o aumento da competitividade local e regional e das instituições e empresas (CASAROTTO e PIRES, 1999).

Boullón (2002) explica que o conceito de região constrói-se fundamentado em diferentes critérios. Destaca que uma forma de regionalização se constitui no interesse de intervir num determinado espaço por questões estratégicas, cujos limites são estabelecidos por decisões político-administrativas, as quais são denominadas regiões-plano ou regiõesprograma. Essas qualidades, válidas para a análise econômica, não podem ser transportadas para o espaço físico, porque vários elementos materiais de natureza diversa compartilham uma mesma unidade espacial. Dessa forma, as regiões denominadas agrícolas são entrecortadas por espaços ocupados por indústrias, e as regiões industriais apresentam áreas utilizadas para agricultura, ou seja, dificilmente, encontram-se regiões totalmente homogêneas.

Ao considerar a concentração de bens e serviços em determinados conglomerados urbanos, os quais têm capacidade de estender sua influência para além de seus limites, abrangendo uma área maior que os rodeia, surge a qualidade de polarização da região. Com base nos conceitos discutidos e nos autores precedentes, pode-se compreender que uma região homogênea não existe, o que ocorre é a superposição de diversas redes que se formam por causa das atividades que se tornam possíveis pelas características físicas locais e pelas interações sociais dos agentes vinculados a um determinado território.

Afirma ainda Boullón (2002) que o planejamento físico tem a finalidade de ordenar as ações do homem sobre o território, ocupando-se em resolver harmonicamente a construção de todo tipo de coisas, bem como antecipar o efeito da exploração dos recursos naturais. É uma tentativa de dar resposta aos problemas causados pelo uso anárquico do solo, em 
razão da expansão da população em termos quantitativos, que trouxe como conseqüência a disputa pelo espaço em exploração e o avanço para outros incultos.

\subsection{Espaço turístico}

Para o turismo, interessa o planejamento do espaço. O espaço turístico é conseqüência da presença e distribuição territorial dos atrativos turísticos que são a matéria-prima dessa atividade. Os planejadores, quando trabalham na determinação do espaço turístico, delimitam num mapa uma superfície de dimensões planas que lhes interessa. Uma característica física dos atrativos é que, mesmo muito próximos, dificilmente se tocam; outra é que, mesmo nos países com densidade de atrativos, existem grandes áreas que carecem deles, acentuando-se sua descontinuidade.

Visto que o espaço turístico é entrecortado, não se pode recorrer a técnicas de regionalização para proceder a sua delimitação porque, de acordo com elas, seria preciso abranger toda a superfície do país ou da região em estudo, e, caso isso fosse feito, grandes superfícies que não são turísticas figurariam como turísticas, cometendo-se um erro. Isso significa que regiões turísticas não existem. É precisamente para substituir a idéia de região turística que desenvolvemos a idéia de espaço turístico (BOULLÓN, 2002 p. 79).

A melhor forma de determinar um espaço turístico, segundo o autor, é recorrer ao método empírico, observando-se as distribuições territoriais dos atrativos e dos empreendimentos, detectando-se os agrupamentos e as concentrações visualmente. Dessa maneira, é possível, por intermédio de procedimentos sistemáticos e de metodologias específicas, encontrar os componentes do espaço turístico, conforme descritos a seguir, de forma descendente em relação à superfície desse espaço.

O primeiro componente com que se pode caracterizar um espaço turístico, segundo Boullón (2002), é a zona turística. Esta se caracteriza como a maior unidade de análise e estruturação do universo espacial turístico de um país, possuindo superfície variável, pois depende da extensão territorial de cada Nação e da forma de distribuição dos seus atrativos turísticos, cuja dimensão mínima é pouco superior à máxima alcançada por um complexo turístico. Para existir, deve contar com um número mínimo de dez atrativos turísticos próximos, sem importar a categoria a que pertencem. Observando-se num mapa a localização exata de todos os atrativos, determina-se visualmente a proximidade deles, utilizando-se a lei da contigüidade.

Além dos atrativos turísticos, para funcionar adequadamente, uma zona deve contar, em seu território, com equipamentos, serviços turísticos e dois ou mais centros turísticos e estar provida de um sistema de transportes e de comunicação que relacione entre si os dois elementos principais e integrem-na com outras zonas e elementos do espaço turístico. Caso careça parcial ou totalmente desses últimos requisitos, deve ser qualificada como zona potencial (BOULLÓN, 2002).

Após delimitar uma zona turística, passa-se a um segundo momento que se destina a verificar a possibilidade de dividi-la em unidades menores, as quais se denominam áreas. Portanto, uma área turística corresponde à parte em que se pode dividir uma zona, constituindo-se em uma superfície menor, dotada de atrativos turísticos contíguos em 
número também menor que a zona e, da mesma forma, necessitando de infra-estrutura de transportes e de comunicação que interligue todos os elementos turísticos que a integram. Para funcionar como subsistema, requer ainda a presença de um centro turístico e se sua infra-estrutura, seus equipamentos e serviços forem insuficientes, é classificada como de potencial turístico.

Para verificar se existe a possibilidade de subdividir uma zona em áreas, observa-se a forma total e procuram-se pontos de estrangulamento. Quando encontrados, os atrativos, que ficaram para cada lado, devem ser contados, pois uma área não pode apresentar menos que dez atrativos, fato que implica a necessidade de uma zona turística possuir, no mínimo, vinte atrativos para que possa ser subdividida (BOULLÓN, 2002).

Feita a análise de um determinado espaço turístico, pode-se dividi-lo em áreas e, definidas as suas limitações, parte-se para a verificação de um terceiro nível de divisão, que são os centros turísticos. Vale lembrar que centro turístico refere-se a todo conglomerado urbano que, em seu território ou em sua área de influência, possui atrativo turístico de tipo e hierarquia suficientes para motivar uma viagem. Para permitir viagens de ida e volta no mesmo dia, o raio de influência é calculado em duas horas de distância-tempo, o que corresponde ao caminho que pode ser percorrido por um ônibus de turismo, que depende das condições das estradas e da topografia, podendo ser utilizado como critério, não como medida exata. De acordo com as condições de deslocamento, a influência do centro turístico pode ser delimitada por, no mínimo, um raio de sessenta e no máximo cento e vinte quilômetros. Em condições excepcionais de tráfego e atratividade turística, considerando-se o deslocamento por automóvel, pode chegar a duzentos quilômetros (BOULLÓN, 2002).

Alerta Boullón (2002) que se torna imprescindível para considerar-se centro turístico: hospedagem; alimentação; entretenimento; agências de viagem de ação local; informações turísticas sobre atrativos e instalações locais; comércio turístico; posto telefônico; correios; telégrafos; sistema de transporte interno organizado, conectando o centro aos diversos atrativos existentes em sua área de influência; e ligação com os sistemas de transporte externo em âmbito nacional, internacional, regional ou local, de acordo com a hierarquia do centro.

Considerando a função que desempenham como locais receptivos, os centros turísticos podem ser classificados em quatro tipos.

1) Centros turísticos de distribuição - são os que servem de base ao turista que visita os atrativos incluídos em seu raio de influência e retornam para dormir. Nesse caso, a totalidade dos meios de hospedagem se localiza na cidade, mas parte dos estabelecimentos de alimentação, comércio turístico, serviço de guias, bem como instalações específicas, como trilhas, mirantes, serviços sanitários, estão situados nos respectivos atrativos turísticos.

2) Centros turísticos de estada - mais comuns que os de distribuição — são os locais em que o turismo passou a se desenvolver por meio da exploração de um único atrativo, por exemplo, as estações de esqui.

O que diferencia um centro de estada de um de distribuição turística é o tempo de permanência do turista no local. Nos centros de distribuição, os turistas permanecem de 
um a três dias, porque sua finalidade é conhecer o maior número possível de atrativos gerenciados partindo daqueles centros. No centro de estada, o turista volta todos os dias ao mesmo atrativo para praticar seu esporte ou suas atividades turísticas preferidas. Por esse motivo, os centros de estada precisam de equipamentos de entretenimento mais diversificados, para oferecer alternativas diferentes durante o período de permanência, principalmente durante tardes e noites (BOULLÓN, 2002).

3) Centros turísticos de escala - cumprem um papel importante, porém são menos comuns que os anteriores. Coincidem com as conexões das redes de transporte e com as etapas intermediárias dos percursos de longa distância entre um local emissor e outro receptor, do próprio país ou do exterior. Dificilmente, a estada em um centro de escala se prolonga mais de uma noite, especialmente, nos localizados em estradas. É comum, nesses locais, haver infra-estrutura para alimentação, abastecimento de automóvel, realização de consertos rápidos, sem pernoite.

4) O último tipo corresponde aos centros turísticos de excursão - que são os que recebem, por menos de 24 horas, turistas procedentes de outros centros.

Ressalta o autor que os atrativos turísticos ocupam lugar de extrema importância, podendo-se afirmar serem a razão dos centros; todavia só se constituem condição imprescindível para os centros de estada, distribuição e excursão (BOULLÓN, 2002).

Existem outros elementos com que se pode classificar um espaço turístico; no entanto, como não se enquadram no estudo aqui realizado, foram desconsiderados. Resta, pois, a análise dos denominados corredores turísticos, que são as vias de conexão entre as zonas, as áreas, os complexos, os centros, os conjuntos, os atrativos turísticos, os locais de origem e os destinos, que funcionam como elementos estruturadores do sistema turístico. De acordo com a função, podem ser corredor turístico de traslado ou de estada.

O primeiro constitui-se da rede de estradas de um país ou de uma região por meio das quais se deslocam os fluxos turísticos. Quando é viável, em função da oferta de opções, devem-se selecionar as estradas que passam pelas melhores paisagens, não importando se o caminho que será percorrido ficará mais longo, porque o tempo despendido é sempre compensado pela beleza da paisagem.

Como nos centros e complexos, também os corredores turísticos estendem sua influência para além de sua própria superfície. Como é longitudinal, o cálculo do seu raio de ação realiza-se com base em parâmetros, isto é, cálculo da faixa de proteção visual, que, dependendo da topografia e do tipo de paisagem, adquire três dimensões: de cinco a dez metros, de cinqüenta a cem metros e até de quinhentos metros.

A faixa de cinco a dez metros é determinada pelas condições morfológicas: quando os caminhos passam entre paredes rochosas, devem ser proibidos quaisquer tipos de escritas ou fixação de cartazes que afetem o seu aspecto natural. A faixa de cinqüenta a cem metros se aplica a locais de paragens arborizadas, exploradas comercialmente. Deve-se manter a aparência da paisagem original em toda a extensão dos territórios por onde passam os corredores turísticos. Quando a vegetação é mata tropical ou subtropical, cinqüenta metros são suficientes; caso sejam bosques de pinheiros, tal faixa deve ser ampliada para cem metros, de forma que impeça a linha visual de ultrapassá-la. Se a paisagem é plana e sem árvores, deve-se estender a faixa para quinhentos metros. Esse ambiente torna o alcance do campo visual até o horizonte, sendo impraticável a criação de barreiras visuais. Nesses 
casos, os artefatos devem ser construídos de forma que preservem o equilíbrio estético da paisagem. Deve-se, inclusive, proibir certos tipos de construções, colocação de placas, cemitério de automóveis ou outras ocupações do solo que prejudiquem a paisagem, a não ser que sejam cercados por barreiras.

Para melhor aproveitar os corredores de traslado, deve-se analisar a sua extensão e identificar atrativos possíveis de despertar o interesse do turista. Os atrativos devem estar localizados até 14 quilômetros da estrada, o equivalente a dez minutos de distância/tempo, se o terreno for plano, o caminho reto ou pavimentado, e não mais que dois quilômetros, caso seja montanhoso e de terra. Parte importante do equipamento turístico deve estar nos corredores de traslado, como postos de gasolina, hotéis, banheiros limpos, entre outros.

O segundo constitui-se de corredores turísticos de estada que desempenham uma função combinada de centro com corredor turístico e que consistem em superfícies alongadas, em geral paralelas às costas de mares, rios ou lagos, com largura não superior a cinco quilômetros.

O que distingue um corredor de estada de um de traslado é, em primeiro lugar, a forma de disposição dos atrativos; em segundo lugar, a forma do assentamento do empreendimento e, por fim, sua função que é decorrente dos dois anteriores (BOULLÓN, 2002).

E também neste caso, o atrativo determina a estrutura física do corredor de estada. Em vez de situar-se em um ponto eqüidistante de um conjunto de atrativos (como se explicou ao descrever as características dos centros turísticos de distribuição) ou de concentrar o equipamento em uma única praia ou um bosque (como ocorre com os centros turísticos de estada), a localização do empreendimento turístico nos corredores de estada pode adotar três formas, a saber: cidade linear, distribuição linear de hospedagem e concentrações escalonadas (BOULLÓN, 2002, p. 102).

Ao concluir esta seção, que teve como objetivo apresentar os conceitos subjacentes ao delineamento da pesquisa e subsidiaram a análise dos dados, ressalta-se que o intuito não foi esgotar o assunto, porém permitir ao leitor compreender os preceitos que orientaram o estudo. Pode-se resumir o aprendizado obtido, apontando alguns aspectos que são relevantes para o entendimento do método de coleta de dados, que será apresentado na seção seguinte, bem como da análise dos resultados que serão discutidos na quarta seção.

Em primeiro lugar, depreende-se da discussão feita que um arranjo produtivo local caracteriza-se por uma evolução do nível de relacionamento entre empresas de um mesmo setor e localizadas num determinado território e que, para assim caracterizar-se, necessita haver um processo de coordenação das organizações que o constituem. É possível também sugerir que, num determinado território, coexista mais de um arranjo produtivo.

Em segundo lugar, com relação à regionalização com vistas ao planejamento, a identificação da área a ser contemplada para os projetos, partindo-se da localização de atrativos turísticos existentes num determinado território, evita a elaboração de projetos isolados, em que elementos turísticos existentes em outro estado ou município, que, na prática, estão interligados, sejam desconsiderados em razão de questões meramente burocráticas. 


\section{Procedimentos para coleta de dados}

O propósito da presente seção é sintonizar os leitores com o método de coleta de dados adotado para a realização da pesquisa. Optou-se por detalhar os procedimentos empregados na coleta de dados em um item específico em virtude de possibilitar uma melhor explicitação dos passos dados pelos pesquisadores a fim de levantar as variáveis necessárias à análise.

Num primeiro momento, realizou-se o inventário turístico de todos os municípios abrangidos pelo projeto do arranjo produtivo local, que, segundo Petrocchi (2001), consiste em um levantamento que se realiza num determinado lugar, com o objetivo de verificar todos os elementos que podem ser aproveitados para o desenvolvimento turístico.

Para a realização do inventário, seguiram-se os seguintes passos:

a) Num primeiro momento, buscou-se, no Sebrae/SC, resgatar diagnósticos turísticos realizados nos anos 1990, nos quais constava um mapeamento preliminar de atrativos turísticos e infra-estrutura da época.

b) Após a obtenção dos diagnósticos turísticos disponibilizados pelo Sebrae, fizeram-se contatos preliminares com as coordenações de turismo dos municípios objetos de estudo, a fim de verificar a validade das informações já disponíveis e obter uma visão preliminar sobre os locais que serviriam de orientação para o levantamento de campo.

c) Após o contato com a coordenação de turismo na Prefeitura Municipal de cada cidade, procedeu-se à observação in loco, em cada um dos atrativos e equipamentos turísticos preliminarmente identificados pelas informações colhidas, conforme descritos nas fases $b$ e $c$, bem como em outros elementos de interesse turístico, descobertos pelos pesquisadores durante os deslocamentos pelos municípios e nos contatos com a população.

d) Durante as visitas para observação dos atrativos turísticos, fez-se o cadastramento de cada um deles, preenchendo-se o formulário correspondente (atrativo natural, cultural, alimentos e bebidas e hospedagem), seguindo-se critérios definidos por Beni (2000). Para o preenchimento do formulário, realizaram-se observações quanto às facilidades de acesso e às condições ambientais do atrativo, levando-se em conta as informações fornecidas pelos proprietários no que tange ao interesse em explorar o turismo local e sobre a existência ou não de algum fluxo ao referido atrativo.

e) Ao mesmo tempo em que se buscavam informações sobre o elemento turístico visitado (atrativo, meio de hospedagem ou alimentação), marcavam-se os pontos geográficos coletados com GPS (Global Positioning System), seguindo as recomendações básicas para o tipo de levantamento, que demandaram cuidados quanto à quantidade mínima de satélites, proximidade de obstruções físicas, eletromagnéticas, condições de umidade e temperatura ambiente.

f) Como se pode observar na Figura 1, os municípios que compõem o Projeto Arranjo Produtivo Local Rota da Amizade não são contíguos. Em virtude da opção pelo uso da teoria do espaço turístico de Boullón (2002), razão pela qual foram marcados os pontos através do GPS dos elementos turísticos nos municípios, conforme já explicitado na alínea anterior, decidiu-se inventariar os atrativos, meios de hospedagem e de alimentação localizados nos municípios de Ibicaré, Luzerna, Lacerdópolis, Ouro e Capinzal, por causa da necessidade de deslocamento a fim de atingir todos os 
municípios do referido projeto. Ressalte-se que, nesse caso, foram inventariados somente os elementos turísticos desses cinco municípios localizados às margens da rodovia, a uma distância de até $14 \mathrm{~km}$, seguindo-se as orientações da metodologia utilizada e já explicitada no marco teórico deste texto.

Figura 1 - Mapa de localização dos municípios integrantes do Arranjo Produtivo Local Rota da Amizade

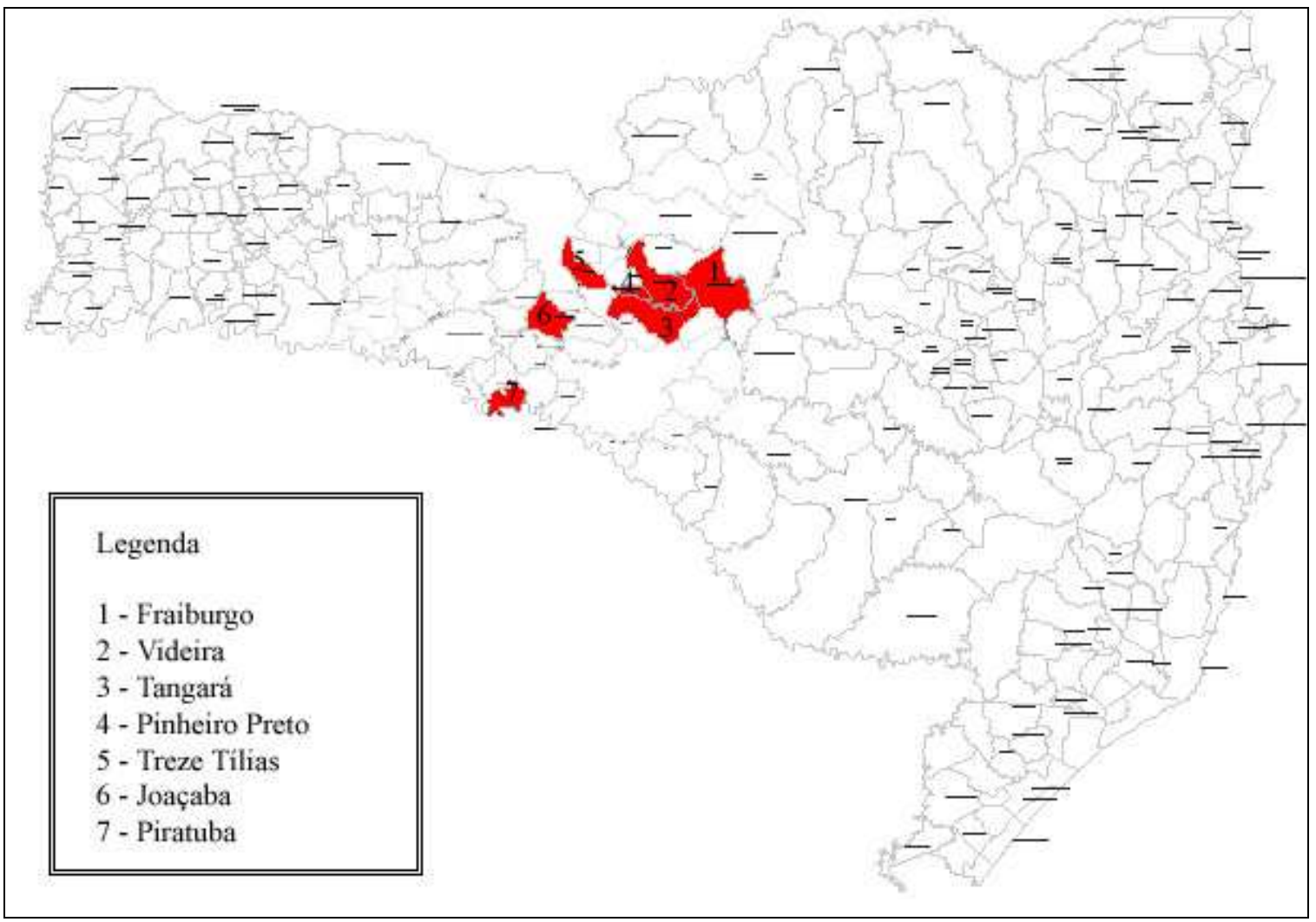

g) Os dados levantados compuseram o documento "Análise de Cenários para Planejamento Turístico da Rota da Amizade", produzido em 2005, que contempla uma série de aspectos, como análise de mercado; análise da infra-estrutura básica e turística; perspectivas de regionalização, que não foram abordados no presente texto por não se relacionar com os objetivos pretendidos para a sua elaboração. Os dados, aqui discutidos, portanto, referem-se a um recorte de um estudo mais amplo.

h) Os pontos colhidos pelo GPS localizam-se na região do Meio-Oeste catarinense, utilizando-se da carta topográfica do IBGE (Instituto Brasileiro de Geografia e Estatística) disponibilizada no site da Epagri (Empresa de Pesquisa Agropecuária e Extensão Rural de Santa Catarina).

i) Após a observação dos pontos no mapa, passou-se à análise, orientando-se pela teoria utilizada como marco teórico, ou seja, determinação hierárquica dos espaços turísticos. Iniciou-se pela demarcação da área global, seguindo-se as orientações oferecidas por Boullón (2002), apresentadas na segunda seção do presente texto, realizando as subdivisões (áreas e centros) e sempre atentando para a existência do número de 
atrativos e das condições mínimas para a classificação de cada uma das subáreas para ficar em acordo com a teoria utilizada.

Nesta seção, portanto, tratou-se do método de coleta de dados utilizado para a realização do trabalho aqui apresentado. Na seguinte, serão apresentados os dados e a sua análise.

\section{Caracterização do arranjo produtivo local com base na teoria dos espaços turísticos}

Antes de abordar as conclusões mais específicas, ou seja, de ater-se à resposta das questões que orientaram o trabalho de pesquisa, retratam-se, nesta seção, as questões mais gerais fundamentadas na revisão bibliográfica. A primeira diz respeito ao entendimento de Cluster, arranjo produtivo e sistemas locais de produção, conceitos bastante controversos e que ainda são objeto de profícuo debate entre os pesquisadores.

Fica claro, com base na revisão bibliográfica, que todos esses conceitos se interligam e correspondem a situações similares; porém, apoiando-se na explicação dos autores consultados, é possível concluir que existem níveis diferentes de integração entre os empreendimentos que compõem um conjunto de empresas.

Quando se refere a cluster, compreende-se que se trata de um aglomerado de empresas num mesmo território, havendo algumas vantagens nessa junção, como serviços especializados, mão-de-obra e instituições de pesquisa; entretanto a ligação entre as empresas é relativamente incipiente. Já um arranjo produtivo local que, no entendimento de Shmitt et al. (2004) e Paiva (2004), é uma evolução do cluster, ocorre quando se inicia um processo de aproximação entre as empresas e algumas estratégias começam a desenvolver-se em conjunto, porém ainda não há um processo de liderança e governança estabelecido. Finalmente o sistema local de produção se dá quando um grupo de empresas de um setor específico inicia um processo de produção com inter-relação intensa, com estratégias comuns, até mesmo desenvolvendo produtos específicos e com a responsabilidade de produção de partes do produto por empresas aderentes ao sistema.

Optou-se, para este trabalho, considerar o conjunto das empresas existentes como um cluster, considerando-se que, nesse território estudado, não há uma integração intensa entre as empresas, pois de um total de mais de duas centenas de empresas existentes na região, apenas setenta inseriram-se no projeto do APL. Esse subconjunto, portanto, poderia ser considerado um arranjo produtivo, por estar num processo de integração, porém não suficientemente forte para que possa ser considerado como um APL em sua totalidade.

Após essas considerações iniciais, parte-se para a apresentação dos dados colhidos na pesquisa que serviu de base para o presente texto. Com a alocação dos pontos correspondentes aos atrativos turísticos no mapa, a contagem dos mesmos e a demarcação da área de abrangência chegou-se a uma configuração do espaço apresentada na Figura 2. Com base na observação da linha que contorna todo o território, entende-se que há possibilidade de classificá-la como uma zona turística, pois, em termos quantitativos, possui um número superior a dez atrativos ( 96 , conforme inventários turísticos), conta com infra-estrutura de alimentação e hospedagem (146, conforme inventários turísticos), além de existirem acessos em boas condições (asfaltados) entre a maioria dos atrativos. 
Após essa primeira demarcação, partiu-se em busca de algum ponto de estrangulamento. A aglomeração dos atrativos e da infra-estrutura turística divide a zona turística em duas áreas: a área 1 (A1), que abrange os municípios localizados entre Piratuba e Luzerna; e a área 2 (A2), com os municípios que envolvem os locais entre Treze Tílias e Fraiburgo, conforme pode ser visto na Figura 2. Optou-se por considerar o ponto de estrangulamento entre os municípios de Luzerna e Ibicaré, para atender à necessidade de se ter pelo menos um centro turístico em cada área.

Embora haja mais de um centro turístico em cada uma das referidas áreas, considerou-se, para a sua definição, que cada local contasse com atrativos suficientes, mas que tivesse pelo menos um município com fluxo regular de turistas. Nesse sentido, a área A1 conta com o município de Piratuba, e a área A2, com o município de Treze Tílias e, quanto à existência de atrativos e infra-estrutura turística, verificaram-se, nos inventários turísticos, que existe, em cada uma delas, um número suficiente. Assim a área A1 dispõe de 26 atrativos e 62 estabelecimentos de alimentação e hospedagem, e a área A2, 70 atrativos turísticos e 84 empreendimentos de alimentação e hospedagem em suas respectivas áreas de abrangência. Observa-se que, quanto ao número de estabelecimentos de infra-estrutura turística (hospedagem e alimentação), as duas áreas possuem um número bastante semelhante; porém, em termos de atrativos, a área A2 apresenta um número bastante superior por existir, ali, pelo menos dois centros turísticos de excursão.

\section{Figura 2 - Caracterização do espaço abrangido pelo Arranjo Produtivo Local Rota da Amizade}

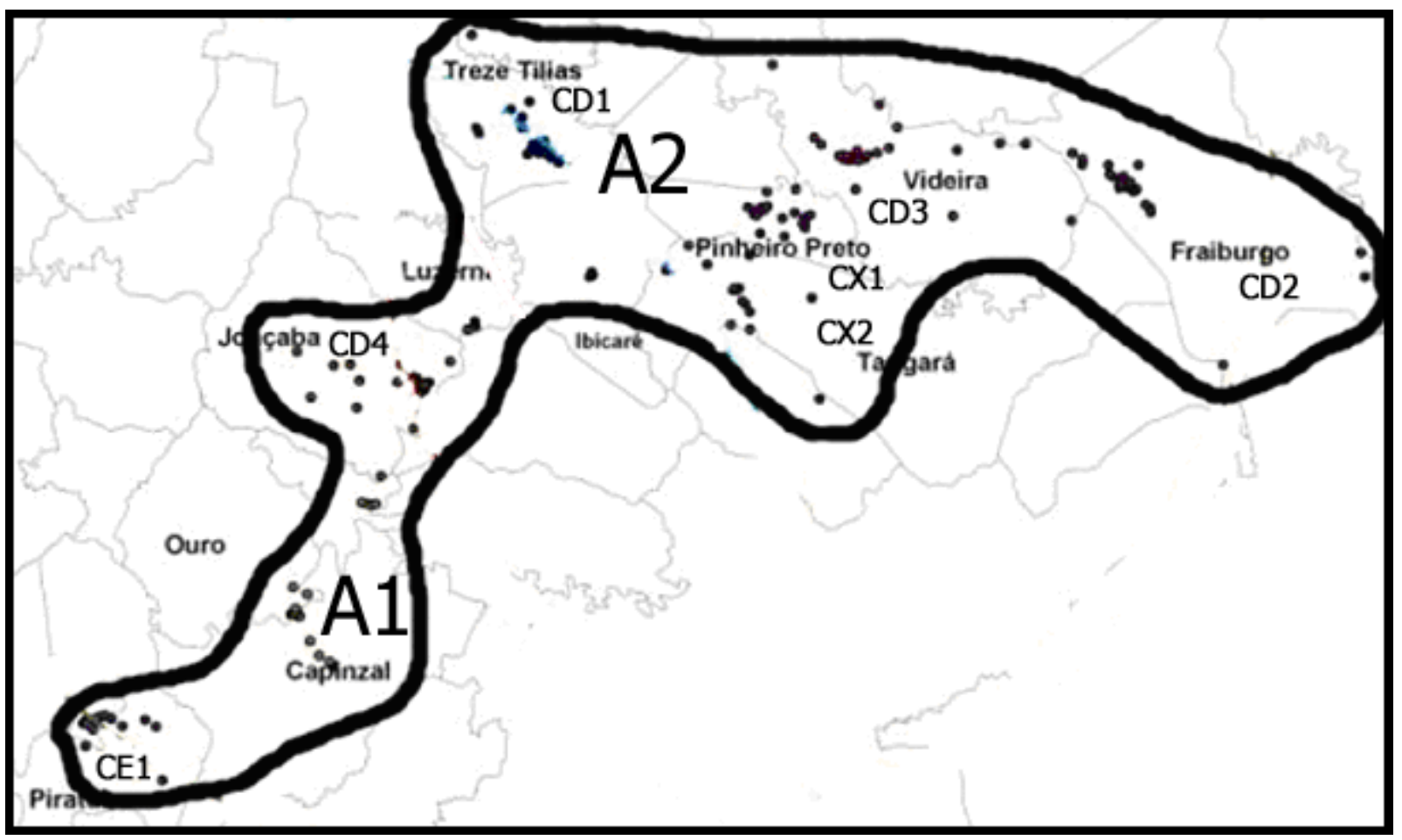

Fonte: adaptado pelos autores de Rota da Amizade, 2005.

Seguindo-se a análise, com base no referencial teórico, considerou-se que os centros de distribuição ou de estada caracterizam-se como conformações urbanas alicerçadas com 
meios de hospedagem. Observando-se os inventários turísticos, identificou-se a existência desses tipos de infra-estrutura nos municípios de Fraiburgo (seis), Videira (quatro), Treze Tílias (12), Joaçaba (sete) e Piratuba (15), levando-se em conta apenas hotéis e pousadas, deixando de lado, pois, casas para locação. Constatou-se ainda que, nos inventários turísticos (ROTA DA AMIZADE, 2005), do município de Treze Tílias, eram cinco e que não havia especificação do número de leitos. Em Piratuba, conforme estimativa da Secretaria de Turismo, o número de leitos oferecidos por casas de aluguel importa num total aproximado de 1.300, o que corresponde a quase um terço dos leitos oferecidos pelos hotéis de todos os municípios inseridos no arranjo produtivo, os quais são 4.050 leitos. Feitas essas considerações, identificaram-se quatro centros de distribuição: um em Treze Tílias (CD1), outro em Fraiburgo (CD2), mais um em Videira (CD3) e mais outro em Joaçaba (CD4), os quais se encontram demarcados no mapa da Figura 2.

Revelou-se, nos dados contidos nos inventários, que o município de Treze Tílias é o que apresenta a maior concentração de meios de hospedagem, seguido de Joaçaba, Fraiburgo e Videira. Comprovou-se também que a área turística A2 possui três centros de distribuição, e a área A1, apenas um, em razão de os atrativos principais existentes em sua área de abrangência serem históricos, culturais e ambientais. A área A1 possui um centro de estada, no município de Piratuba (CE1), que foi construído, a partir dos anos 1970 (ROGGE, 1999), por causa da exploração das águas termais, e seu fluxo principal depende do interesse do turista em banhar-se nas águas, retornando todos os dias ao mesmo atrativo. Pode-se inferir que é similar ao comportamento do turista que se desloca para atrativos esportivos e de montanhas. No que diz respeito a oportunidades de entretenimento, o município de Piratuba apresenta limitações (somente três), o que, provavelmente, é superado por eventos, pois, conforme o inventário, ali se realiza o maior número de eventos (dezesseis), entre todos os municípios da região.

Pode-se também observar no mapa (Figura 2) a identificação na área A1 de um centro de distribuição, localizado em Joaçaba, e assim classificado porque apresenta atrativos do tipo que não motiva o turista a visitá-los mais de uma vez, sendo similares aos de Treze Tílias, Videira e Fraiburgo.

Pela análise feita, não se identifica, na região, nenhum município que apresente a condição de centro de escala. Dos municípios que compõem o arranjo produtivo, objeto de análise, Pinheiro Preto e Tangará assumem a tipologia espacial de centros de excursão, pois, conforme verificado em seus inventários, possuem 18 e nove atrativos, respectivamente, além de um razoável número de grupos atuando com manifestações culturais. Os dois municípios não exibem infra-estrutura de hospedagem e, atualmente, já atendem visitantes que se hospedam nos municípios de Fraiburgo, Treze Tílias e Piratuba, além de um público regional, constituindo-se em centros de excursão em potencial, conforme se observa na Figura 2 na qual são identificados como CX1 e CX2.

Analisando-se de forma global e considerando-se as distâncias entre os municípios, que distam menos de $60 \mathrm{~km}$ entre eles e em torno de $120 \mathrm{~km}$ de uma ponta a outra da zona turística, ou seja, entre Piratuba e Fraiburgo, infere-se que, mesmo que sejam classificados como centros de distribuição, cada um dos municípios serve também como centros de excursão uns dos outros, o que possibilita a oferta de maiores opções de entretenimento ao turista. Nesse sentido, a iniciativa dos empresários que originou a Rota da Amizade pode ser um indício do seu potencial. 
Observando-se a configuração do arranjo produtivo, verifica-se que existe a possibilidade de deslocamento entre os atrativos, porém ainda não estruturada, a fim de oferecer opções de escolha quanto aos melhores caminhos, visto que nem todos estão com a infra-estrutura básica adequada (asfalto, condições de tráfego de ônibus de turismo). Também não existe interferência do setor na adequação das áreas adjacentes quanto à estética no sentido anteriormente exposto, sendo visíveis e sentidos, por meio do olfato, a existência de construções que desfiguram a paisagem, como pocilgas, galinheiros, que necessitam da atenção para melhoria da imagem da região.

Também, observando-se o mapa, nota-se que existem municípios não-pertencentes ao projeto, entretanto de passagem obrigatória nos deslocamentos entre os centros turísticos e as áreas aqui identificadas, haja vista não haver alternativa de deslocação por outras rodovias, quais sejam: Ibicaré, Luzerna, Lacerdópolis, Ouro e Capinzal. Mesmo não fazendo parte do projeto, observou-se, pela alocação dos pontos no mapa, que esses municípios possuem, ao longo da rodovia, locais de interesse, os quais não estão fazendo parte do projeto, pelo menos até o momento em que se realizou a pesquisa. Em princípio, pôde-se verificar que, na região, não existe nenhum local com características especiais para originar um corredor de estada — há somente para corredor de traslado.

Outro fator que se evidencia, com base na observação da Figura 3 (que considera uma distância de $60 \mathrm{~km}$ do seu centro), é a interferência das áreas de abrangência de cada um dos centros turísticos, devendo ser cuidadosamente analisada na construção dos roteiros turísticos, pois, conforme verificado nos inventários, os atrativos de todos eles (exceto, talvez, Piratuba) se constituem dos mesmos tipos (natureza, história e cultura), podendo, como alerta Boullón (2002), caso não sejam planejados de forma que um centro possa complementar o outro, constituir-se em concorrentes uns dos outros, dividindo a demanda.

O conhecimento desses elementos, descritos até aqui, são importantes quando se pretende planejar o espaço turístico. Outrossim, é preciso verificar mais alguns pontos integrantes do sistema turístico - a demanda, a interdependência entre os diversos espaços e a preparação do produto - e fazer a integração entre todos para que sejam obtidos melhores resultados. 
Figura 3 - Área de abrangência dos centros turísticos

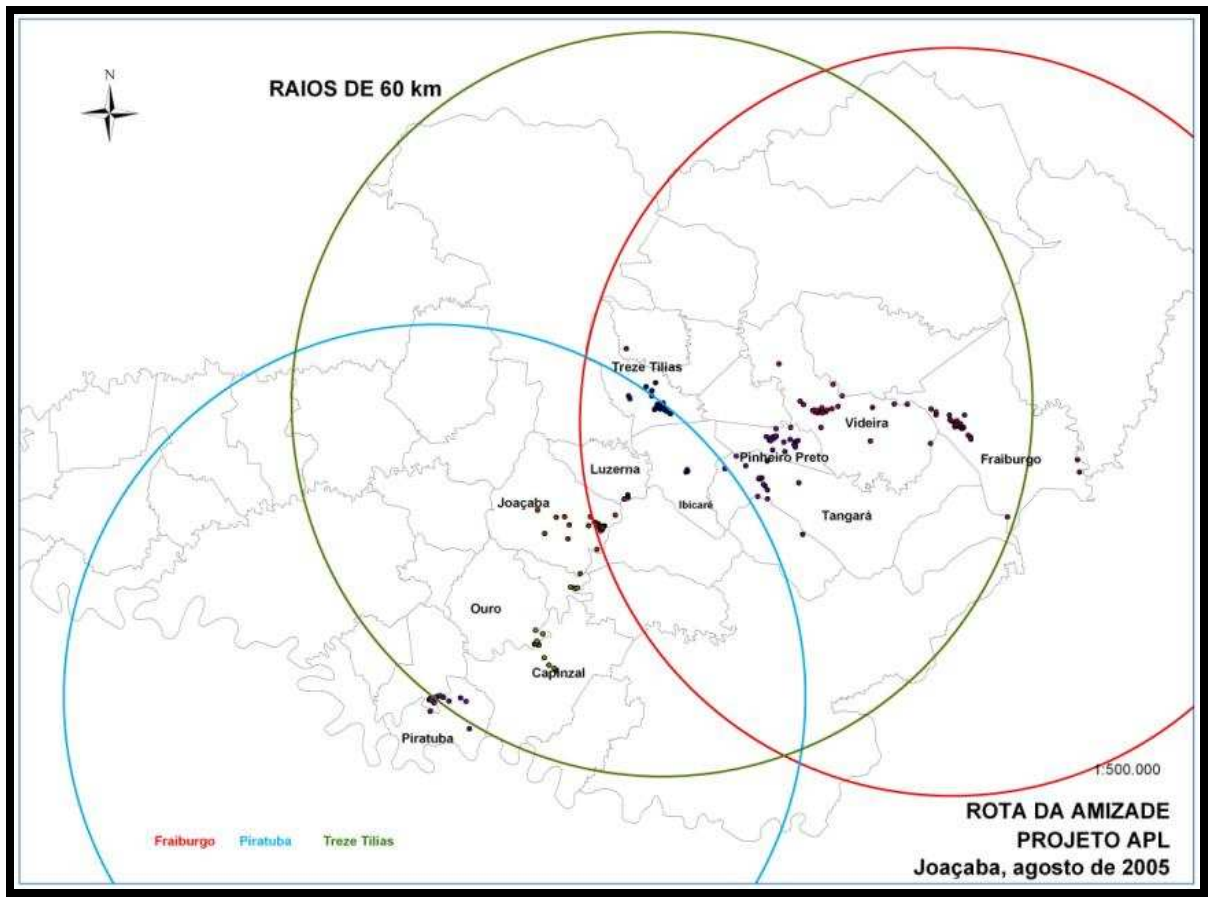

Fonte: Rota da Amizade, 2005.

Esses aspectos, entretanto, não foram discutidos aqui por não se constituírem em elementos importantes para a análise, visto que o principal interesse foi o de analisar a área de abrangência dos municípios pertencentes ao Arranjo Produtivo Local Rota da Amizade com base na teoria dos espaços.

\section{Considerações finais}

Antes das referências às conclusões obtidas com o trabalho, é conveniente reconhecer os seus limites, pois se trata de uma primeira tentativa de analisar a região por um critério pouco utilizado no Brasil, que, por serem mais fáceis, utilizam as divisões políticoadministrativas existentes. No passado, a análise espacial do turismo possuía limitações em função da necessidade de se alocar manualmente a localização dos atrativos dificultando sobremaneira o trabalho; entretanto, atualmente, com a tecnologia disponível, utilizam-se outros meios que facilitam esse tipo de análise.

A análise dos dados foi essencialmente a da localização dos atrativos e empreendimentos hoteleiros, não sendo considerada a hierarquia dos mesmos, muito menos as diferenças de capacidade de atração de visitantes de cada um dos centros. Outro fator que limita o estudo refere-se à questão da territorialidade, pois ocorrem conflitos quando os planejadores pretendem atuar nos corredores turísticos, implicando interesses de grupos distintos, muitas vezes, não ligados diretamente à exploração do turismo. Convém ressaltar também, que, em virtude da utilização dos inventários turísticos realizados especificamente para os municípios pertencentes ao arranjo, considerando-se a área de abrangência de sessenta quilômetros de cada cidade, há de se supor que possam existir atrativos turísticos em 
condições de serem integrados à zona turística, os quais não foram identificados. Esses limites, porém, não invalidam o trabalho até aqui apresentado, constituindo-se em oportunidades para aprofundamento em futuros trabalhos.

Entende-se que se caracterizou a região como uma zona turística que se divide em duas áreas a A1 que se localiza a oeste de Ibicaré, e a A2, a leste, visto que se optou por considerar o estrangulamento da região na divisa entre este município com Luzerna, seguindo-se a metodologia apresentada por Boullón (2002). Também se verificou, conforme os critérios adotados, que a região possui quatro centros de distribuição (CD1 Treze Tílias, CD2 - Fraiburgo, CD3 - Videira e CD 4 - Joaçaba) e um de estada (CE1 Piratuba), além de dois centros de excursão (CX1 - Pinheiro Preto e CX2 - Tangará).

Fica evidente a necessidade de se estudar, com mais atenção, o relacionamento entre os municípios que fazem parte do projeto e os adjacentes, especialmente, Ibicaré, Luzerna, Lacerdópolis, Ouro e Capinzal, pois são passagens obrigatórias para os turistas que se deslocam entre os diversos centros. Não se trata de envolver somente os municípios como instituições, mas também, e principalmente, os empreendedores e atrativos existentes nas áreas de abrangência dos corredores turísticos.

O estudo aqui apresentado serve, pois, para subsidiar tanto os planejadores como os professores, especialmente por considerar a necessidade de adotarem-se critérios mais adequados na delimitação de áreas para intervenção por meio da inserção do turismo como atividade econômica. Não há pretensão de esgotar o assunto, o que se espera é contribuir com idéias que possam intensificar o debate e melhorar o nível de conhecimento sobre o turismo e sua contribuição para o desenvolvimento regional.

Em virtude dos limites já apontados, o estudo abre perspectivas para futuros trabalhos. Uma perspectiva que se vislumbra é fundamentar-se em outra premissa, ou seja, antes de realizar o inventário e a demarcação dos pontos com o GPS, identificar os clusters utilizando-se métodos já bastante difundidos em economia, como o de quociente locacional, especialmente se o interesse do investigador for um estado ou país. Isso permitirá demarcar a área a ser inventariada na distância de sessenta quilômetros da aglomeração hoteleira, que, pelos critérios aqui discutidos, poderia ser considerada um centro turístico. Esse procedimento parece ser interessante uma vez que possibilita uma visão mais abrangente.

Ainda é preciso debruçar-se sobre questões de territorialidade, pois existem, na região, diversas redes que se sobrepõem (agroindústria, por exemplo), e, por essa razão, podem ocorrer conflitos de interesses o que dificultaria o desenvolvimento do turismo.

Outro aspecto que não foi objeto de discussão se refere à hierarquização dos atrativos existentes na região, por não se constituir numa variável essencial para o tipo de análise que se pretendia; entretanto esse enfoque pode identificar os municípios com maior potencial de atração de turistas e, fundamentando-se nesse conhecimento, por exemplo, delinear as estratégias de roteirização turística, enfatizar a divulgação, supondo-se que esses seriam os responsáveis pelo interesse da demanda pela região. Enfim, existem outros tantos temas importantes para o entendimento do turismo como fator de desenvolvimento; fica-se, entretanto, nos citados em virtude de estarem mais relacionados com o estudo aqui apresentado. 


\section{Referências}

ALEXANDRE NETO, P. A integração espacial, economias de rede e inovação. Lisboa: Instituto Piaget, 1997.

BENI, M. C. Análise estrutural do turismo. São Paulo: Senac, 2000.

BENKO, G. A ciência regional. Oeiras: Celta, 1999.

BOULlón, R. C. Planejamento do espaço turístico. Bauru: Edusc, 2002.

BRASIL. Ministério do Turismo. Programa de regionalização do turismo - roteiros do Brasil. Brasília, DF: Ministério do Turismo, 2004.

CASROTTO FILHO, N.; PIRES, L. H. Redes de pequenas e médias empresas e desenvo/vimento regional. São Paulo: Atlas, 2001.

CAVACO, C. Turismo rural e desenvolvimento local. In: RODRIGUES, A. B. Turismo e geografia: reflexões teóricas e enfoques regionais. São Paulo: Hucitec, 1999.

FRANCO, A. Por que precisamos de desenvolvimento local integrado e sustentável. 2. ed. Brasília: Instituto de Política, 2000.

GOLDRATT, E. M.; COX, J. A meta um processo de aprimoramento contínuo. São Paulo: Educator, 1994.

HAIR JR., J. F.; BABIN, B.; MONEY, A. H.; SAMOUEL, P. Fundamentos de métodos de pesquisa em administração. São Paulo: Bookman, 2005.

HARVEY, D. A condição pós-moderna. São Paulo: Loyola, 1992.

OLIVEIRA, A. P. Turismo e desenvolvimento: planejamento e organização. São Paulo: Atlas, 2001.

PETROCCHI, M. Gestão de pólos turísticos. São Paulo: Futura, 2001.

PORTER, M. E. Vantagem competitiva: criando e sustentando um desempenho superior. Rio de Janeiro: Campus, 1990. 1999. . Competição: estratégias competitivas essenciais. 12. ed. Rio de Janeiro: Elsevier,

ROCA, Z.; OLIVEIRA, J. Identerra - identidade territorial no desenvolvimento das regiões ultraperiféricas. In: 1a . Conferência do Atlântico. Madeira: Ceged, 2004.

ROGGE, C. V. Estudo sobre motivação e características da clientela das águas termais de Piratuba - SC, 1999. [76 p.] Monografia (Programa Pós-Graduação em Turismo e Hotelaria). Centro de Ciências Sociais Aplicadas, Universidade do Oeste de Santa Catarina, Joaçaba, 1999.

ROTA DA AMIZADE. Análise de cenários para planejamento turístico. (Documento) Joaçaba: Sebrae, 2005.

SOUZA, M. J. L. de. O território: sobre espaço e poder, autonomia e desenvolvimento. In: CASTRO, I. E. et al. (org.). Geografia: conceitos e termos. Rio de Janeiro: Bertrand Brasil, 1995. 
SCHMITT, C. L. et al. Concentração de empresas: estratégia para a competitividade e a eficiência coletiva. In: CONGRESSO LATINO-AMERICANO DE ESTRATÉGIA - SLADE, 17., 2004, Itapema. Anais... Itapema: Univali, 2004.

SEAKARAN, U. Research methods for business: a skill-building approach. 2. ed. New York: Juhn Wiley, 1992.

SILVEIRA, R. L. M. Globalização, espacialidade e região. Rio de Janeiro: UERJ, 2004. Disponível em: www.igeo.uerj.br/VICBG-2004. Acesso em: 25 abr. 2006.

\footnotetext{
${ }^{\text {i }}$ Uma primeira versão do presente texto foi apresentada ao GT "Turismo e Gestão Organizacional” e publicada nos Anais do IV Seminário de Pesquisa e Turismo do Mercosul — SEMINTUR e III ANPTUR — Seminário da Associação Nacional de Pesquisa e Pós Graduação em Turismo realizado em Caxias do Sul — RS, no período de 7 a 8 de julho de 2006.
} 